\title{
MORFODIAGNOSE DE Psidium guajava L., MYRTACEAE
}

\section{MORPHO-DIAGNOSIS OF Psidium guajava L., MYRTACEAE}

\author{
DUARTE, M. do R. *; PAULA, F. M. de \\ Laboratório de Farmacognosia, Departamento de Farmácia, Universidade Federal do Paraná (UFPR) \\ *Autor para correspondência: Av. Pref. Lothário Meissner, 632, 80210-170, Curitiba, PR, \\ marciard@ufpr.br
}

\begin{abstract}
RESUMO
Psidium guajava L., denominada popularmente de goiabeira, é uma espécie arbustiva a arbórea de pequeno porte, pertencente à família Myrtaceae e nativa da América tropical. As folhas são empregadas na medicina tradicional para tratamento de diarréia, disenteria e cólica abdominal. Possui flavonóides, em especial quercetina, tendo sido comprovadas as atividades antidiarréica, espasmolítica, antimicrobiana e antioxidante. Este estudo analisou a anatomia foliar e caulinar de $P$. guajava, com o objetivo de fornecer dados morfodiagnósticos aplicáveis ao controle de qualidade. O material vegetal foi fixado, seccionado à mão livre e corado com azul de astra e fucsina básica. Testes microquímicos foram também realizados. A folha é hipoestomática, com estômatos paracíticos, e apresenta tricomas tectores unicelulares. No limbo, ocorrem epiderme uniestratificada, camadas subepidérmicas parenquimáticas junto à superfície adaxial e cavidades secretoras. $O$ mesofilo tende a dorsiventral e a nervura central e o pecíolo são percorridos por um feixe vascular bicolateral envolto por bainha esclerenquimática. $\mathrm{O}$ caule apresenta cilindros vasculares contínuos de floema externo, xilema e floema interno, atravessados por raios estreitos. Cristais de oxalato de cálcio e células com conteúdo fenólico ocorrem na folha e no caule.
\end{abstract}

Palavras-chave: Anatomia, farmacognosia, flavonóides, goiabeira, planta medicinal

\begin{abstract}
Psidium guajava L., commonly named as guava, is a shrub or small tree which belongs to the Myrtaceae family and is indigenous to tropical America. The leaves are used in folk medicine for treating diarrhea, dysentery and abdominal cramps. It has flavonoids, quercetin in particular, and antidiarrheic, antispasmodic, antimicrobial and anti-oxidant effects were confirmed. This study has analysed the foliar and caulinar anatomy of $P$. guajava, aiming to supply morpho-diagnostic information needed to quality control. The plant material was fixed, freehand sectioned and stained with astra blue and basic fuchsine. Microchemical tests were also conducted. The leaf is hypostomatic, presenting paracytic stomata, and has unicellular non-glandular trichomes. In the blade, it occurs uniseriate epidermis, parenchymatic sub-epidermal layers next to the adaxial surface and secretory cavities. The mesophyll is dorsiventral-like and the midrib and petiole are traversed by a bicollateral bundle encircled by a sclerenchymatic sheath. The stem shows continuous vascular cylinders of external phloem, xylem and internal phloem, traversed by narrow rays. Calcium oxalate crystals and cells containing phenolic compounds are seen in the leaf and stem.
\end{abstract}

Keywords: Anatomy, flavonoids, guava, medicinal plant, pharmacognosy

\section{INTRODUÇÃO}

A família Myrtaceae inclui 80 gêneros e 3000 espécies, distribuídas em regiões tropicais e subtropicais, com centros de dispersão na Austrália e América (JUDD et al., 1999). É representada por várias espécies medicinais, entre elas, Psidium guajava L. (Fig. 1). Esta é denominada comumente de goiabeira em português, guava em inglês e guayabo em espanhol (LOZOYA et al., 2002), e é freqüentemente cultivada, em razão 
dos frutos comestíveis em pomares domésticos ou plantações comerciais para a indústria alimentícia (LORENZI, 1992).

Planta rústica, que atinge porte arbustivo ou arbóreo com menos de $10 \mathrm{~m}$, é considerada nativa da América tropical, em especial do Brasil e das Antilhas (SILVA, 2001). O tronco é tortuoso, liso e descamante e as folhas são simples e de textura coriácea, de 8-12cm de comprimento por 3-6cm de largura (LORENZI, 1992).

As folhas de $P$. guajava são empregadas popularmente para tratar desordens gastrointestinais, prática herdada originariamente da medicina asteca no México (LOZOYA et al., 2002). Infusos ou decoctos preparados com folhas frescas ou desidratadas são indicados para diarréia, disenteria, flatulência e cólica abdominal. 0 efeito espasmolítico e antidiarréico está relacionado com o conteúdo em flavonóides, em particular de derivados da quercetina, que atuam como antagonistas do cálcio nas fibras musculares lisas (MORALES, LOZOYA, 1994). Adicionalmente, comprovaramse as atividades antimicrobiana, antitussígena (JAIARJ et al., 1999), sedativa (LUTTERODT, MALEQUE, 1988), antioxidante (MARTIN et al., 1998; WANG, 2000; NADERI et al., 2003; ANJANEYULU, CHOPRA, 2004; WOODMAN, CHAN, 2004) e antiproliferativa para células cancerígenas (MANOSROI, DHUMTANOM, MANOSROI, 2005).

Diferentes edições da Farmacopéia Brasileira definem as folhas (FARMACOPÉIA, 2003) e as cascas de caule (SILVA, 1926) como sendo as partes usadas da droga, para a qual taninos, flavonóides e óleos essenciais são considerados os marcadores químicos (FARMACOPÉIA, 2003). Devido à comercialização de folhas de goiabeira como fitoterápico, freqüentemente acompanhadas de caule, e à escassez de estudos anatômicos com enfoque na caracterização farmacobotânica, este trabalho tratou da morfodiagnose foliar e caulinar de $P$. guajava, fornecendo informações aplicáveis ao controle de qualidade.

\section{MATERIAL E MÉTODOS}

O material botânico foi coletado no Horto de Plantas Medicinais, do Departamento de Farmácia, da Universidade Federal do Paraná, cujas coordenadas são de $25^{\circ} 26^{\prime} 45^{\prime \prime S}$ e $49^{\circ} 14^{\prime} 25^{\prime \prime} \mathrm{W}$ e cuja altitude é de $931 \mathrm{~m}$, em agosto de 2005 . A exsicata foi identificada por taxonomista como equivalente à depositada sob registro MBM186045 no Museu Botânico Municipal de Curitiba.

Amostras de folhas adultas e de fragmentos de caules, obtidos a $5 \mathrm{~cm}$ do ápice dos ramos, foram fixadas em FAA 70 (JOHANSEN, 1940) e mantidas em etanol a $70 \%$ (BERLYN, MIKSCHE, 1976). Esse material foi seccionado à mão livre, nos sentidos transversal e longitudinal, e corado com a dupla coloração azul de astra e fucsina básica (ROESER, 1962). Testes microquímicos foram efetuados para evidenciar lignina com floroglucina clorídrica (SASS, 1951), compostos fenólicos com cloreto férrico (JOHANSEN, 1940), amido com lugol (BERLYN, MIKSCHE, 1976), substâncias lipofílicas com Sudan III (FOSTER, 1949) e oxalato de cálcio com ácido sulfúrico (OLIVEIRA, AKISUE, 1989). Foram obtidas fotomicrografias no microscópio óptico Olympus BX40 acoplado à unidade de controle PM20 . 


\section{RESULTADOS}

\section{Folha}

Em vista frontal do limbo, as células epidérmicas exibem paredes anticlinais espessas, de contorno praticamente poligonal (Fig. 2A, 2B). Estômatos paracíticos localizam-se exclusivamente na face abaxial, caracterizando a folha como hipoestomática (Fig. 2B). Inserem-se no mesmo nível das células adjacentes e as células-guarda mostram crista cuticular externa evidente (Fig.3B). Tricomas tectores unicelulares (Fig. 2D), de paredes espessas e ponta aguda encontram-se em ambas as superfícies foliares. Uma cutícula com espessura moderada reveste a epiderme (Fig. $2 \mathrm{E}, 2 \mathrm{~F}$ ) e forma flanges cuticulares especialmente na face abaxial da região nervural (Fig. 3B, 3C).

A epiderme é unisseriada e, subjacentemente à face adaxial, notam-se cerca de três camadas subepidérmicas parenquimáticas, cujas células apresentam alguns cloroplastos e paredes anticlinais comparativamente mais altas que as do sistema de revestimento (Fig. 2C, 2E, 2F). O mesofilo tende a dorsiventral, consistindo de parênquimas paliçádico e esponjoso pouco diferenciados (Fig. 2C). O primeiro é formado de cerca de quatro estratos de células estreitas, enquanto o segundo constituise de três camadas de células mais curtas e largas. Feixes vasculares colaterais de pequeno porte, envoltos por bainha parenquimática, percorrem o mesofilo (Fig. 2C).

A nervura central é levemente côncava na face adaxial e convexa na oposta. O parênquima paliçádico se interrompe na porção central, onde se observam aproximadamente quatro camadas de colênquima anelar. No lado oposto, ocorrem três camadas desse sistema sustentação. Mergulhado no parênquima fundamental, há um feixe vascular bicolateral, em forma praticamente de arco fechado, circundado por bainha esclerenquimática multiestratificada e quase completa (Fig. 3A). Raios parenquimáticos estreitos atravessam o floema externo, o xilema e o floema interno (Fig. 3A, 3D, 3E). Neste, ocorrem algumas fibras em meio aos elementos crivados e células parenquimáticas. Amiloplastos estão presentes no colênquima e são freqüentes no parênquima fundamental. O pecíolo se assemelha à nervura central e exibe algumas células pétreas, isoladas ou em pequenos grupos, nas proximidades do feixe vascular bicolateral, junto à face adaxial.

Numerosos prismas e drusas de oxalato de cálcio são encontrados na folha (Fig. $2 \mathrm{E}$ ), principalmente na nervura central (Fig. 3E). Várias cavidades secretoras, de formato circular, revestidas de epitélio com citoplasma denso e cujo produto secretado é de cor amarela e natureza lipofílica, localizam-se no limbo (Fig. 2F), inclusive na nervura central (Fig. 3A, 3C), e no pecíolo, preferencialmente nas proximidades do sistema de revestimento. Compostos fenólicos são evidenciados no interior das células parenquimáticas da folha.

\section{Caule}

O caule revela secção circular e é revestido pela periderme (Fig. 4B), cujas camadas de súber se destacam parcialmente. O córtex compõe-se de parênquima cortical multiestratificado (Fig. 4A, 4B), contendo compostos fenólicos e abundantes amiloplastos, e apresenta uma bainha esclerenquimática completa (Fig. 4A), formada de algumas fibras e predominantemente de células pétreas. $O$ arranjo vascular é bicolateral. Uma segunda bainha esclerenquimática, semelhante à primeira e ocasionalmente incompleta, encontra-se no floema externo (Fig. 4A, 4C). Raios 
parenquimáticos, consistindo de uma fileira de células, percorrem o floema e o xilema (Fig. 4A, 4C). Essas células possuem tamanho relativamente grande e contêm compostos fenólicos e amiloplastos.

Drusas e numerosos prismas de oxalato de cálcio são encontrados no córtex, no floema e na medula. Esta região também mostra vários amiloplastos, células parenquimáticas com conteúdo fenólico e células pétreas, isoladas ou formando pequenos grupamentos.

\section{DISCUSSÃO}

Os aspectos anatômicos foliares de $P$. guajava são concordantes com os descritos para a família, no que diz respeito à presença de tricomas tectores simples e unicelulares, cavidades secretoras nas proximidades da epiderme, feixe vascular do tipo bicolateral percorrendo a nervura central e cristais de oxalato de cálcio (METCALFE, CHALK, 1950). Adicionalmente, esses autores mencionam a ocorrência de hipoderme junto à face epidérmica superior, que é equivalente à camada subepidérmica descrita neste trabalho, assim denominada pelo fato de não se ter realizado estudo ontogenético do órgão foliar de $P$. guajava. Por outro lado, a FARMACOPÉIA (1988-2003) e TANTAWY (2004) atribuem epiderme multisseriada a essa espécie, muito provavelmente sem adotar o rigor nomenclatural que envolve a definição de hipoderme e epiderme multisseriada.

Essas estruturas são coincidentemente relatadas por JORGE (1992), para quem, entretanto, a nervura central é percorrida por três feixes vasculares bicolaterais envoltos por bainha lignificada e o mesofilo é homogêneo em paliçada. Na presente investigação, distingue-se um único feixe bicolateral circundado por bainha esclerenquimática no nível analisado e o mesofilo tende a ser dorsiventral, uma vez que o parênquima clorofiliano próximo da face abaxial não se apresenta como parênquima esponjoso típico, compondo-se de células com morfologia intermediária entre lobada e em paliçada. Esses caracteres são corroborados por TANTAWY (2004) para a mesma espécie, autor que também observa a interrupção do parênquima paliçádico na região da nervura central. A FARMACOPÉIA (1988-2003) difere ao indicar a presença de feixes vasculares bicolaterais em arco aberto e de pequenas cavidades secretoras nos floemas externo e interno na nervura central.

METCALFE e CHALK (1950) afirmam que o padrão geral de estômato para as Myrtaceae é anomocítico, sendo o tipo paracítico relatado menos freqüentemente. Divergindo da ocorrência usual, $P$. guajava possui estômatos paracíticos, encontrados exclusivamente na superfície abaxial. Constatação similar foi apresentada por JORGE (1992), ao estudar a mesma espécie vegetal. Todavia, a FARMACOPÉIA(1988-2003)e TANTAWY (2004) apresentam dados parcialmente contrastantes, este ao analisar exemplares de $P$. guajava cultivados no Egito, verificando estômatos anomocíticos em folha hipoestomática. A estes, RIVERA-ARCE, GATTUSO e LOZOYA (2003) somam o tipo anisocítico em representantes provenientes do México. Adicionalmente, de acordo com esses autores, as cavidades secretoras presentes na folha são de origem esquizolisígena.

Com referência aos aspectos caulinares, estes são compatíveis com a descrição geral para Myrtaceae, tais como, periderme localizada perifericamente em decorrência da instalação do felogênio nas camadas externas do córtex, arranjo bicolateral do sistema vascular, floema e xilema formando cilindros contínuos percorridos por raios 
estreitos, faixas esclerenquimáticas no floema externo, cristais de oxalato de cálcio e numerosas células com conteúdo fenólico (METCALFE, CHALK, 1950). Esses caracteres estruturais relatados no presente estudo são confirmados para caule de $P$. guajava por TANTAWY (2004). Com relação à região da casca, que compreende a periderme até o floema externo, a descrição se assemelha à apresentada por SILVA (1926).

\section{CONCLUSÕES}

Como esperado, os aspectos anatômicos foliares e caulinares descritos neste trabalho para $P$. guajava são compatíveis com os dados relativos à família Myrtaceae. Para a caracterização farmacobotânica, os dados observados devem considerados em conjunto, muito embora tricoma tector unicelular, cavidade secretora, camada subepidérmica parenquimática junto à superfície adaxial na folha, arranjo bicolateral e bainhas esclerenquimáticas no córtex e no floema do caule possam ser propostos como parâmetros morfodiagnósticos.

Artigo Recebido 06/05 Aceito 09/05

\section{REFERÊNCIAS}

ANJANEYULU, M.; CHOPRA, K. Quercetin, an anti-oxidant bioflavonoid, attenuates diabetic nephropathy in rats. Clin.Exp.Pharmacol.Physiol., Carlton, v. 31, n. 4, p. 2448, 2004.

RIVERA-ARCE, E.; GATTUSO, M.; LOZOYA, X. Anatomical identity parameters of the crude drug Psidii guajavae folium. Pharm.Biol., Lisse, v. 41, n. 7, p. 516-21, 2003.

BERLYN, G. P.; MIKSCHE, J. P. Botanical microtechnique and cytochemistry. Ames: lowa State University, 1976. p. 121, 276.

FARMACOPÉIABrasileira. 4.ed. São Paulo: Atheneu, 1988-2003. s.p.

FOSTER, A. S. Practical plant anatomy. $2^{\text {nd }}$ ed. Princeton: D.Van Nostrand, 1949. p. 218.

JAIARJ, P.; KHOOHASWAN, P.; WONGKRAJANG, Y.; PEUNGVICHA, P.; SURIYAWONG, P.; SUMAL-SARAYA, M. L.; RUANGSOMBOON, O. Anticough and antimicrobial activities of Psidium guajava Linn. leaf extract. J.Ethnopharmacol., Limerick, v. 67, p. 203-12, 1999.

JOHANSEN, D. A. Plant microtechnique. New York: McGraw-Hill Book, 1940. p. 41, 193.

JORGE, L. I. F. Caracterização farmacobotânica e microscopia alimentar de seis espécies brasileiras de Myrtaceae Jussieu. São Paulo, 1992. s.p. Dissertação (Mestrado em Fármaco e Medicamentos) Faculdade de Ciências Farmacêuticas da Universidade de São Paulo.

JUDD, W. S.; CAMPBELL, C. S.; KELLOGG, E. A.; STEVENS, P. F. Plant systematics: a phylogenetic approach. Sunderland: Sinauer, 1999. p. 321-3. 
LORENZI, H. Árvores brasileiras: manual de identificação e cultivo de plantas arbóreas nativas do Brasil. Nova Odessa: Plantarum, 1992. p. 269.

LOZOYA, X.; REYES-MORALES, H.; CHÁVEZ-SOTO, M. A.; MATÍNEZ-GARCÍA, M. C.; SOTO-GONZÁLEZ, Y.; DOUBOVA, S. V. Intestinal anti-spasmodic effect of a phytodrug of Psidium guajava folia in the treatment of acute diarrheic disease. J.Ethnopharmacol., Limerick, v. 83, p. 19-24, 2002.

LUTTERODT, G. D.; MALEQUE, A. Effects on mice locomotor-activity of a narcotic-like principle from Psidium guajava leaves. J.Ethnopharmacol., Limerick, v. 24, n. 2/3, p. 219-31, 1988.

MANOSROI, J.; DHUMTANOM, P.; MANOSROI, A. Anti-proliferative activity of essential oil extracted from Thai medicinal plants on KB and P388 cell lines. Cancer Lett., Limerick, p. 1-7, 2005.

MARTIN, M. J.; LA-CASA, C.; ALARCON-DE-LA-LASTRA, C.; CABEZA, J.; VILLEGAS, I.; MOTILVA, V. Anti-oxidant mechanisms involved in gastroprotective effects of quercetin. J.Biosci., Bangalore, v. 53, n. 1/2, p. 82-8, 1998.

METCALFE, C. R.; CHALK, L. Anatomy of dicotyledons: leaves, stem, and wood in relation to taxonomy. Oxford: Clarendon, 1950. v. 1, p. 620-31.

MORALES, M. A.; LOZOYA, X. Calcium-antagonist effects of quercetin on aortic smooth-muscle. Planta Med., Stuttgart, v. 60, n. 4, p. 313-7,1994.

NADERI, G. A.; ASGARY, S.; SARRAF-ZADEGAN, N.; SHIRVANY, H. Anti-oxidant effect of flavonoids on the susceptibility of LDL oxidation. Mol.Cell.Biochem., Hingham, v. 246, n. 1/2, p. 193-6, 2003.

OLIVEIRA, F.; AKISUE, G. Fundamentos de farmacobotânica. Rio de Janeiro: Atheneu, 1989. p. 48.

ROESER, K. R. Die Nadel der Schwarzkiefer-Massenprodukt und Kunstwerk der Natur. Mikrokosmos, Stuttgart, v. 61, p. 33-6, 1962.

SASS, J. E. Botanical microtechnique. $2^{\text {nd }}$ ed. Ames: lowa State College, 1951. p. 97.

SILVA, R. A. D. Pharmacopéia dos Estados Unidos do Brasil. São Paulo: Nacional, 1926. p. 489.

SILVA, S. P. Frutas no Brasil. São Paulo: Nobel, 2001. p. 117-118.

TANTAWY, M. E. Morpho-anatomical study on certain taxa of Myrtaceae. Asian J.Plant Sci., s.I., v. 3, n. 3, p.274-85, 2004.

WANG, H. K. The therapeutic potential of flavonoids. Expert Opin.Invest.Drugs, London, v. 9, n. 9, p. 2103-19, 2000. 
WOODMAN, O. L.; CHAN, E. C. Vascular and anti-oxidant actions of flavonols and flavones. Clin.Exp.Pharmacol.Physiol., Carlton, v. 31, n. 11, p. 786-90, 2004.

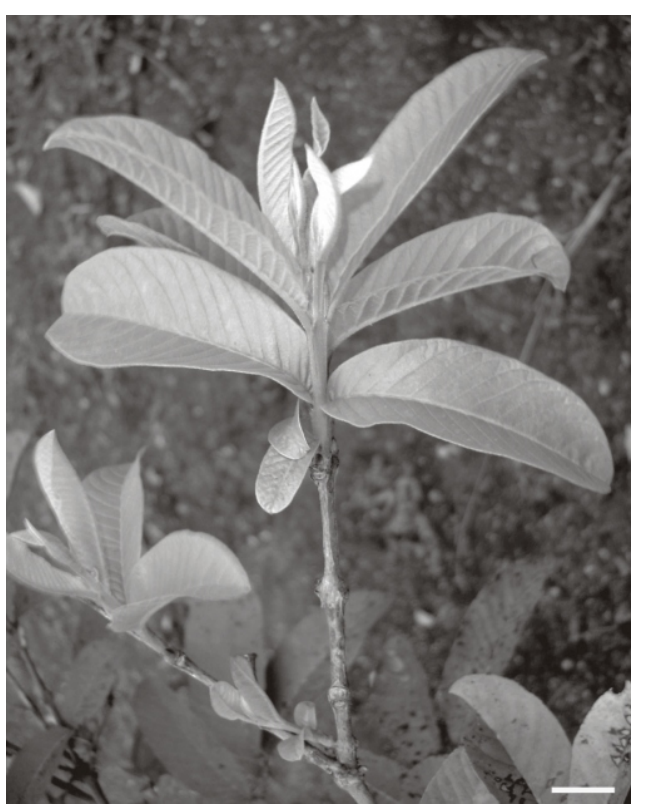

FIGURA 1. PSIDIUM GUAJAVA L., MYRTACEAE ASPECTO DE UM RAMO VEGETATIVO. BARRA = 2cm

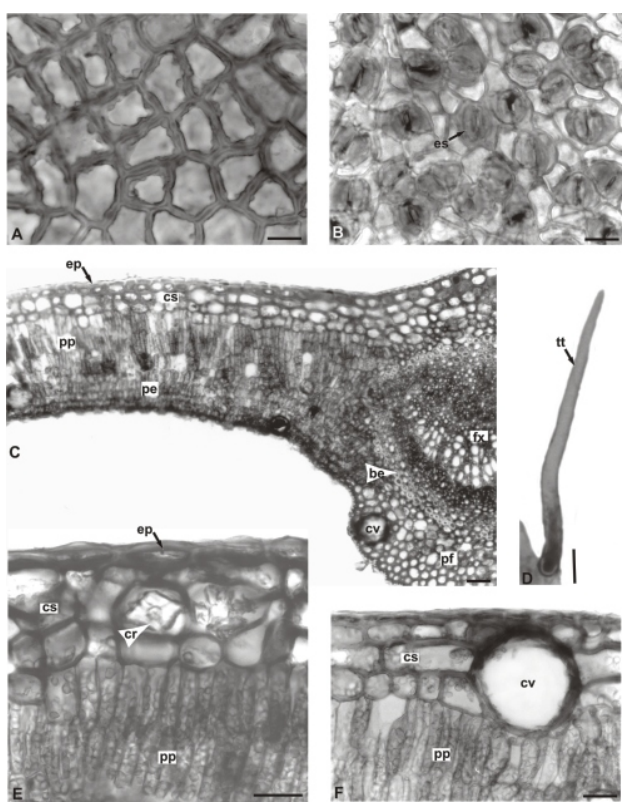

FIGURA 2. P. GUAJAVA FOLHA: A, B. VISTA FRONTAL DA EPIDERME FOLIAR, FACES ADAXIAL E ABAXIAL, RESPECTIVAMENTE; C. SECÇÃO TRANSVERSAL DO LIMBO E PARTE DA NERVURA CENTRAL; D. DETALHE DE UM TRICOMA TECTOR; E. CRISTAIS DE OXALATO DE CÁLCIO NAS CAMADAS SUBEPIDÉRMICAS; F. CAVIDADE SECRETORA. BE BAINHA ESCLERENQUIMÁTICA, CR CRISTAL DE OXALATO DE CÁLCIO, CS CAMADA SUBEPIDÉRMICA, CV CAVIDADE SECRETORA, EP EPIDERME, ES ESTÔMATO, FX FEIXE VASCULAR, PE PARÊNQUIMA ESPONJOSO, PF PARÊNQUIMAFUNDAMENTAL, PP PARÊNQUIMAPALIÇÁDICO, TT TRICOMATECTOR. BARRA $=20 \mu \mathrm{m}$ (A, B, D-F), $50 \mu \mathrm{m}$ (C) 

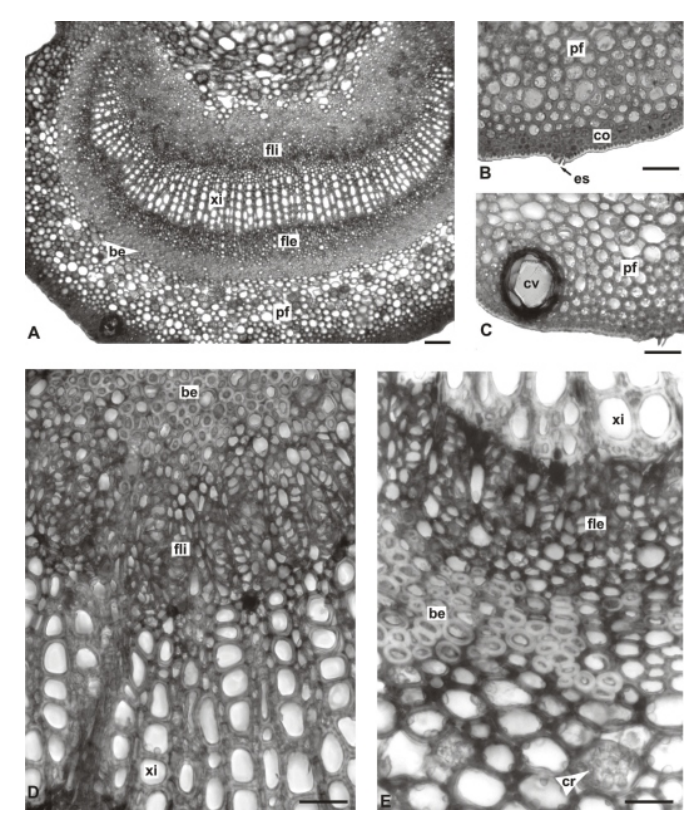

FIGURA 3. P. GUAJAVA NERVURA CENTRAL FOLIAR: A. FEIXE VASCULAR BICOLATERAL; B. ESTÔMATO; C. CAVIDADE SECRETORA; D. FLOEMA INTERNO E XILEMA; E. XILEMA, FLOEMA EXTERNO, BAINHA ESCLERENQUIMÁTICA E CRISTAIS DE OXALATO DE CÁLCIO. BE BAINHA ESCLERENQUIMÁTICA, CO COLÊNQUIMA, CR CRISTAL DE OXALATO DE CÁLCIO, CV CAVIDADE SECRETORA, FLE FLOEMA EXTERNO, FLI FLOEMA INTERNO, PF PARÊNQUIMA FUNDAMENTAL, XI XILEMA. BARRA = 20 $\mu \mathrm{m}(\mathrm{B}-\mathrm{E}), 50$ $\mu \mathrm{m}(\mathrm{A})$
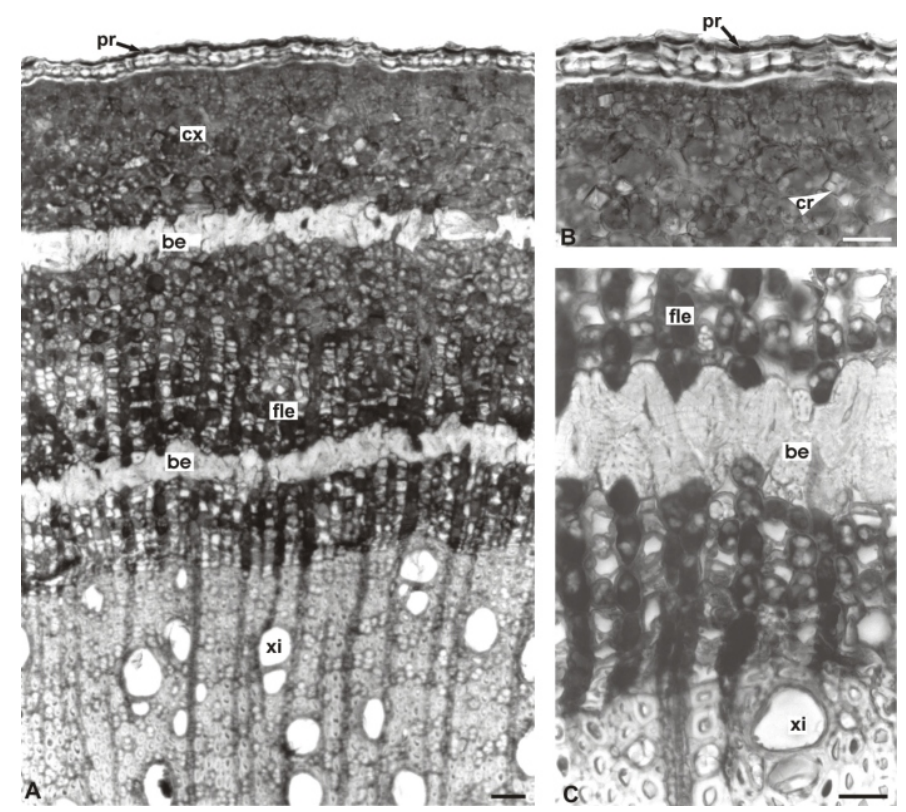

FIGURA 4. P. GUAJAVA CAULE: A. SECÇÃO TRANSVERSAL, MOSTRANDO SISTEMA DE REVESTIMENTO, CÓRTEX E PARTE DO CILINDRO VASCULAR; B. CRISTAL DE OXALATO DE CÁLCIO NO CÓRTEX; C. PORMENOR DABAINHAESCLERENQUIMÁTICANO FLOEMAEXTERNO. BE BAINHAESCLERENQUIMáTICA, CR CRISTAL DE OXALATO DE CálCIO, CX CóRTEX, FLE FLOEMAEXTERNO, PR PERIDERME, XI XILEMA. BARRA? $=20 \mu \mathrm{m}(\mathrm{B}, \mathrm{C}), 50 \mu \mathrm{m}(\mathrm{A})$. 